\title{
22
}

\section{The Problem of Truth \\ in the Light of \\ Recent Discussion}

The question: What is Truth? is a typical philosophical problem. But it has been by no means at all times equally prominent throughout the history of philosophy. The ages in which it has come to the front have been those wherein, as at present, a keenly critical spirit has been predominant. At such times metaphysical interests are more or less subordinated, for a while, to the problems about method, to logical researches, or to the investigations which constitute a Theory of Knowledge.

Such periods, as we know, have recurred more than once since scholastic philosophy declined. And such a period was that which Kant dominated. But the sort of inquiry into the nature of truth which Kant's doctrine initiated quickly led, at the close of the eighteenth century, to a renewed passion for metaphysical construction. The problem regarding the nature of truth still occupied a very notable place in the doctrine of Fichte. It constituted one of the principal concerns, also, of Hegel's so much neglected and ill-understood "Phänomenologie des Geistes." And yet both in the minds of the contemporaries of Fichte and of Hegel, and still

An address delivered before the International Congress of Philosophy at Heidelberg, in September, I9o8. [Reprinted from WJO, pp. i $87-254$. 
more in those of their later disciples and opponents, the problem of truth went again into the background when compared with the metaphysical, the ethical, and the theological interests which constructive idealism and its opponents, in those days, came to represent. Hence wherever one looks, in the history of philosophical opinion between 1830 and 1870 , one sees how the problem of truth, although never wholly neglected, still remained, for some decades, out of the focus of philosophical interest.

But the scene rapidly changed about and after the year 1870 . Both the new psychology and the new logic, which then began to flourish, seemed, erelong, almost equally to emphasize the importance of a reconsideration of the problem as to the nature of truth. These doctrines did this, especially because the question whether logic was henceforth to be viewed as a part of psychology became once more prominent, so soon as the psychological researches then undertaken had attracted the strong interest of the philosophical public. And meanwhile the revived interest in Kant, growing, as it did, side by side with the new psychology, called for a reinterpretation of the problems of the critical philosophy. The reawakening of Idealism, in England and in America, called attention, in its own way, to the same problem. The modern philosophical movement in France,-a movement which was, from the outset, almost equally made up of a devotion to the new psychology and of an interest in the philosophy of the sciences, has coöperated in insisting upon the need of a revision of the theory of truth. And to complete the story of the latest philosophy, recent tendencies in ethics, emphasizing as they have done the problems of individualism, and demanding a far-reaching reconsideration of the whole nature of moral truth, have added the weight of their own, often passionate, interest to the requirements which are here in question.

The total result is that we are just now in the storm and stress of a reëxamination of the whole problem of truth. About this problem the philosophical interest of to-day centers. Consequently, whether you discuss the philosophy of Nietzsche or of mathematics,-whether the Umwertung aller Werte or the "class of all classes,"-whether Mr. Russell's "Contradiction" or the Uebermensch is in question,--or whether none of these things attract you at all, so that your inquiries relate to psychology, or to evolution, or to the concepts of the historical sciences, or to whatever other region of philosophy you please,-always the same 
general issue has sooner or later to be faced. You are involved in some phase of the problem about the nature of truth.

So much, then, as a bare indication of the historical process which has led us into our present position. I propose, in the present address, to offer an interpretation of some of the lessons that, as I think, we may learn from the recent discussions of the problem whose place in all our minds I have thus indicated.

\section{I}

It seems natural to begin such a discussion by a classification of the main motives which are represented by the principal recent theories regarding the nature of truth. In enumerating these motives I need not dwell, in this company, upon those historical inferences and traditions whose presence in recent thought is most easily and universally recognized. That Empiricism,--due to the whole history of the English school, modified in its later expressions by the Positivism of a former generation, and by the types of Naturalism which have resulted from the recent progress of the special sciences,-that, I say, such empiricism has affected our modern discussion of the nature of truth,--this we all recognize. I need not insist upon this fact. Moreover, the place which Kant occupies in the history of the theory of truth,-that again is something which it is needless here to emphasize. And that the teaching of Fichte and of Hegel, as well as still other idealistic traditions, are also variously represented by present phases of opinion regarding our problem, we shall not now have to rehearse. I presuppose, then, these historical commonplaces. It is not, however, in terms of these that I shall now try to classify the motives to which the latest theories of truth are due.

These recent motives, viewed apart from those unquestionably real influences of the older traditions of the history of philosophy are, to my mind, three in number:

First, there is the motive especially suggested to us modern men by the study of the history of institutions, by our whole interest in what are called evolutionary processes, and by a large part of our recent psychological investigation. This is the motive which leads many of us to describe human life altogether as a more or less progressive adjustment to a natural environment. This motive incites us, therefore, to judge all human products and all human 
activities as instruments for the preservation and enrichment of man's natural existence. Of late this motive, whose modern forms are extremely familiar, has directly affected the theory of truth. The result appears in a part, although not in the whole, of what the doctrines known as Instrumentalism, Humanism, and Pragmatism have been of late so vigorously teaching, in England, in America, in Italy, in France, and, in still other forms, in Germany.

From the point of view which this motive suggests, human opinions, judgments, ideas, are part of the effort of a live creature to adapt himself to his natural world. Ideas and beliefs are, in a word, organic functions. And truth, in so far as we men can recognize truth at all, is a certain value belonging to such ideas. But this value itself is simply like the value which any natural organic function possesses. Ideas and opinions are instruments whose use lies in the fact that, if they are the right ones, they preserve life and render life stable. Their existence is due to the same natural causes that are represented in our whole organic evolution. Accordingly, assertions or ideas are true in proportion as they accomplish this their biological and psychological function. The value of truth is itself a biological and psychological value. The true ideas are the ones which adapt us for life as human beings. Truth, therefore, grows with our growth, changes with our needs, and is to be estimated in accordance with our success. The result is that all truth is relative as it is instrumental, as human as it is useful.

The motive which recent Instrumentalism or Pragmatism expresses, in so far as it takes this view of the nature of truth, is of course in one sense an ancient motive. Every cultivated nation, upon beginning to think, recognizes in some measure such a motive. The Greeks knew this motive, and deliberately connected both the pursuit and the estimate of truth with the art of life in ways whose problematic aspects the Sophists already illustrated. Socrates and his followers, and later the Stoics as well as the Epicureans, also considered, in their various ways, this instrumental aspect of the nature of truth. And even in the Hindoo Upanishads one can find instances of such humanistic motives influencing the inquiry into the problem of truth. But it is true that the historical science of the nineteenth century, beginning, as it did, with its elaborate study of the history of institutions, and culminating in the general doctrines regarding evolution, has given to this motive an importance and a conscious definiteness such as makes its recent 
embodiment in Pragmatism a very modern and, in many ways, a novel doctrine about the nature of truth.

\section{II}

But closely bound up with this first motive in our recent thinking there is a second motive, which in several ways very strongly contrasts with the first. Yet in many minds these two motives are so interwoven that the writers in question are unaware which motive they are following when they utter their views about the nature of truth. No doubt one may indeed recognize the contrasts between these motives, and may, nevertheless, urge good reasons for following in some measure both of them, each in its own way. Yet whoever blindly confuses them is inevitably led into hopeless contradictions. As a fact, a large number of our recent pragmatists have never learned consciously to distinguish them. Yet they are indeed easy to distinguish, however hard it may be to see how to bring them into a just synthesis.

This second motive is the same as that which, in ethics, is responsible for so many sorts of recent Individualism. It is the motive which in the practical realm Nietzsche glorified. It is the longing to be self-possessed and inwardly free, the determination to submit to no merely external authority. I need not pause to dwell upon the fact that, in its application to the theory of truth, precisely as in its well-known applications to ethics, this motive is Protean. Every one of us is, I suppose, more or less under its influence.

Sometimes, this motive appears mainly as a skeptical motive. Then it criticizes, destructively, traditional truth and thereupon leaves us empty of all assurances. But sometimes it assumes the shape of a sovereign sort of rationalism, whereby the thinking subject, first rebelling against outer authority, creates his own laws, but then insists that all others shall obey these laws. In other cases, however, it takes the form of a purely subjective idealism, confident of its own but claiming no authority. Or again, with still different results, it consciously unites its ethical with its theoretical interests, calls itself "Personal Idealism," and regards as its main purpose, not only the freeing of the individual from all spiritual bondage, theoretical and practical, but also the winning for him of an inner harmony of life. In general, in its highest as in some of its less successful embodiments, when it considers the sort of 
truth that we ought most to pursue, this motive dwells, as Professor Eucken has so effectively taught it to dwell, upon the importance of a Lebensanschauung as against the rigidity and the pretended finality of a mere Weltanschauning.

But meanwhile, upon occasion, this same motive embodies itself in various tendencies of the sort known as Irrationalism. In this last case, it points out to us how the intelligence, after all, is but a single and a very narrow function of our nature, which must not be allowed to supersede or even too much to dominate the rest of our complex and essentially obscure, if fascinating, life. Perhaps, on the very highest levels of life, as it hereupon suggests to us: Gefübl ist alles. If not, then at all events, we have the alternative formula: Im Anfang war die Tat. Or, once again, the solving word of the theory of truth is Voluntarism. Truth is won by willing, by creative activities. The doer, or perhaps the deed, not only finds, but $i s$, the truth. Truth is not to be copied, but to be created. It is living truth. And life is action.

I have thus attempted to indicate, by well-known phrases, the nature of this second motive,-one whose presence in our recent theories of truth I believe that you will all recognize. Despite the Protean character and (as you will at once see) the mutually conflicting characters of its expressions, you will observe, I think, its deeper unity, and also its importance as an influence in our age. With us at present it acts as a sort of ferment, and also as an endless source of new enterprises. It awakens us to resist the most various kinds of doctrinal authority,-scientific, clerical, academic, popular. It inspires countless forms of Modernism, both within and without the boundaries of the various confessions of Christendom. As an effective motive, one finds it upon the lowest as also upon the highest levels of our intellectual and moral life. In some sense, as I have said, we all share it. It is the most characteristic and the most problematic of the motives of the modern world. Anarchism often appeals to it; yet the most saintly form of devotion, the most serious efforts for the good of mankind, and our sternest and loftiest spiritual leaders, agree in employing it, and in regarding it as in some sense sacred.

Our age shares this motive with the age of the French Revolution, of the older Idealistic movement, and of the Romantic School. All the more unfortunate, as I think, is the fact that many who glory in the originality of their own recent opinions about the 
nature of truth, know so little of the earlier history of this motive, read so seldom the lesson of the past, and are thus so ill-prepared to appreciate both the spiritual dignity and the pathetic paradox of this tendency to make the whole problem of truth identical with the problem of the rights and the freedom of the individual.

\section{III}

I turn herewith to the third of the motives that I have to enumerate. In its most general form it is a very ancient and familiar motive. It is, indeed, very different from both of the foregoing. Superficially regarded, it seems, at first sight, less an expression of interests that appear ethical. At heart, however, it is quite as deep a motive as either of the others, and it is in fact a profoundly ethical motive as well as a genuinely intellectual one. One may say that, in a sense and to some degree, it pervades the whole modern scientific movement, is present wherever two or three are gathered together for a serious exchange of scientific opinions, and is, in most cases, the one motive that, in scientific assemblies, is more or less consciously in mind whenever somebody present chances to refer to the love of truth, or to the scientific conscience of his hearers.

I have called this third on our list of motives an ancient motive. It is so. Yet in modern times it has assumed very novel forms, and has led to scientific and, in the end, to philosophical enterprises which, until recently, nobody would have thought possible.

It would be unwise at this point to attempt to define this motive in abstract terms. I must first exemplify it. When I say that it is the motive to which the very existence of the exact sciences is due, and when I add the remark that our scientific common sense knows this motive as the fondness for dispassionately weighing evidence, and often simply names it the love of objectivity, I raise more questions in your minds regarding the nature of this motive than at this point I can answer. If, however, anybody suggests, say from the side of some form of recent pragmatism, that I must be referring to the nowadays so deeply discredited motives of a pure "Intellectualism," I repudiate at once the suggestion. The motive to which I refer is intensely practical. Men have lived and died for it, and have found it incstimably precious. I know of no motive purer or sweeter in human life. Meanwhile, it indeed 
chances to be the motive which has partially embodied itself in Pure Mathematics. And neither the tribe of Nietzsche nor the kindred of the instrumentalists have been able justly to define it.

What I am just now interested to point out is that this motive has entered, in very novel ways, into the formulation of certain modern theories of truth. And when I speak of its most novel forms of expression, the historical process to which I refer is the development of the modern critical study of the foundations of mathematics.

To philosophical students in general the existence of metageometrical researches, which began at the outset of the nineteenth century, has now been made fairly familiar. But the non-Euclidean geometry is but a small fragment of that investigation of the foundations of mathematical truth which went on so rapidly during the nineteenth century. Among the most important of the achievements of the century in this direction were the new definitions of continuity and the irrational numbers, the modern exact theory of limits, and the still infant theory of Assemblages. Most important of all, to my mind, were certain discoveries in the field of Logic of which I shall later say a word. I mention these matters here as examples of the influence of a motive whose highly technical applications may make it seem to one at a distance hopelessly intellectualistic, but whose relation to the theory of truth is close, just because, as I think, its relation to truly ethical motives is also extremely intimate.

The motive in question showed itself at the outset of the nineteenth century, and later in the form of an increased conscientiousness regarding what should be henceforth accepted as a rigid proof in the exact sciences. The Greek geometers long ago invented the conception of rigid methods of proof and brought their own methods, in certain cases, very near to perfection. But the methods that they used proved to be inapplicable to many of the problems of modern mathematics. The result was that, in the seventeenth and eighteenth centuries, the mathematical sciences rapidly took possession of new realms of truth, but in doing so sacrificed much of the old classic rigidity. Nevertheless, regarded as the instrumentalists now desire us to regard truth, the mathematical methods of the eighteenth century were indeed incomparably more successful in adjusting the work of the physical sciences to the demands of experience than the methods of the 
Greek geometers had ever been. If instrumentalism had been the whole story of man's interest in truth, the later developments would have been impossible. Nevertheless the modern scientific conscience somehow became increasingly dissatisfied with its new mathematical possessions. It regarded them as imperfectly won. It undertook to question, in a thousand ways, its own methods and its own presuppositions. It learned to reject altogether methods of proof which, for a time, had satisfied the greatest constructive geniuses of earlier modern mathematics. The result has been the development of profoundly novel methods, both of research and of instruction in the exact sciences. These methods have in many ways brought to a still higher perfection the Greek ideal of rigid proof. Yet the same methods have shown themselves to be no mere expressions of a pedantic intellectualism. They have meant clearness, self-possession, and a raising of the scientific conscience to higher levels. Meanwhile, they proved potent both in conquering new realms and in discovering the wonderful connections that we now find linking together types of exact truth which at first sight appeared to be hopelessly diverse.

In close union with the development of these new methods in the exact sciences, and, as I may say, in equally close union with this new scientific conscience, there has gradually come into being a reformed Logic,-a logic still very imperfectly expounded in even the best modern textbooks, and as yet hardly grasped, in its unity, by any one investigator,-but a logic which is rapidly progressing, which is full of beauty, and which is destined, I believe, profoundly to influence, in the near future, our whole philosophy of truth. This new logic appears to offer to us an endless realm for detailed researches. As a set of investigations it is as progressive as any instrumentalist can desire. The best names for it, I think, are the names employed by several different thinkers who have contributed to its growth. Our American logician, Mr. Charles Peirce, named it, years ago, the Logic of Relatives. Mr. Russell has called it the Logic, or the Calculus, of Relations. Mr. Kempe has proposed to entitle it the Theory of Mathematical Form. One might also call it a new and general theory of the Categories. Seen from a distance, as I just said, it appears to be a collection of highly technical special researches, interesting only to a few. But when one comes into closer contact with any one of its serious researches, one sees that its main motive is such as to interest every truthful and reflective 
inquirer who really grasps that motive, while the conception of truth which it forces upon our attention is a conception which neither of the other motives just characterized can be said adequately to express.

In so far as the new logic has up to this time given shape to philosophical theories of truth, it in part appears to tend towards what the pragmatists nowadays denounce as Intellectualism. As a fact Mr. Bertrand Russell, the brilliant and productive leader of this movement in England, and his philosophical friend Mr. George Moore, seem to regard their own researches as founded upon a sort of new Realism, which views truth as a realm wholly independent of the constructive activities by which we ourselves find or pursue truth. But the fact that Mr. Charles Peirce, one of the most inventive of the creators of the new logic, is also viewed by the Pragmatists as the founder of their own method, shows how the relation of the new logic to the theory of truth is something that still needs to be made clear. As a fact, I believe that the outcome of the new logic will be a new synthesis of Voluntarism and Absolutism.

What I just now emphasize is, that this modern revision of the concepts of the exact sciences, and this creation of a new logic, are in any case due to a motive which is at once theoretical and ethical. It is a motive which has defined standards of rigidity in proof such as were, until recently, unknown. In this sense it has meant a deepening and quickening of the scientific conscience. It has also seemed, in so far, to involve a rejection of that love of expediency in thinking which is now a favorite watchword of pragmatists and instrumentalists. And when viewed from this side the new logic obviously tends to emphasize some form of absolutism, to reject relativism in thinking, to make sterner requirements upon our love of truth than can be expressed in terms of instrumentalism or of individualism. And yet the motive which lies beneath this whole movement has been, I insist, no barren intellectualism. The novelty of the constructions to which this motive has led,-the break with tradition which the new geometry (for instance) has involved,-such things have even attracted, from a distance, the attention of some of the least exactly trained of the pragmatist thinkers, and have aroused their hasty and uncomprehending sympathy. "This non-Euclidean geometry," they have said, "these novel postulates, these "freie Schöpfungen des menschlichen 
Geistes' (as Dedekind, himself one of the great creative minds of the new logical movement, has called the numbers),--well, surely these must be instances in favor of our theory of truth. Thus, as we should have predicted, novelties appear in what was supposed to be an absolutely fixed region. Thus (as Professor James words the matter), human thought 'boils over,' and ancient truths alter, grow, or decay." Yet when modern pragmatists and relationists use such expressions, they fail to comprehend the fact that the new discoveries in these logical and mathematical fields simply exemplify a more rigid concept of truth than ever, before the new movement began, had been defined in the minds of the mathematicians themselves. The non-Euclidean geometry, strange to say, is not a discovery that we are any freer than we were before to think as we like regarding the system of geometrical truth. It is one part only of what Hilbert has called the "logical analysis" of our concept of space. When we take this analysis as a whole, it involves a deeper insight than Euclid could possibly possess into the unchangeable necessities which bind together the system of logical relationships that the space of our experience merely exemplifies. Nothing could be more fixed than are these necessities. As for the numbers, which Dedekind called "freie Schöpfungen,"-well, his own masterpiece of logical theory is a discovery and a rigid demonstration of a very remarkable and thoroughly objective truth about the fundamental relations in terms of which we all of us do our thinking. His proof that all of the endless wealth of the properties of the ordinal numbers follows from a certain synthesis of two of the simplest of our logical conceptions, neither one of which, when taken alone, seems to have anything to do with the conception of order or of number,-this proof, I say, is a direct contribution to a systematic theory of the categories, and, as such, is, to the logical inquirer, a dramatically surprising discovery of a realm of objective truth, which nobody is free to construct or to abandon at his pleasure. If this be relativism, it is the relativism of an eternal system of relations. If this be freedom, it is the divine freedom of a self-determined, but, for that very reason, absolutely necessary fashion of thought and of activity.

Well,-to sum up,-this third motive in modern inquiry has already led us to the discovery of what are, for us, novel truths regarding the fundamental relations upon which all of our thought and all of our activity rest. These newly discovered truths possess 
an absoluteness which simply sets at naught the empty trivialities of current relativism. Such truth has, in fact, the same sort of relation to the biologically "instrumental" value of our thinking processes as the Theory of Numbers (that "divine science," as Gauss called it) has to the account books of the shopkeeper.

And yet, as I must insist, the motive that has led us to this type of absolutism is no pure intellectualism. And the truth in question is as much a truth about our modes of activity as the purest voluntarism could desire it to be. In brief, there is, I believe, an absolute voluntarism, a theory of the way in which activities must go on if they go on at all. And, as I believe, just such a theory is that which in future is to solve for us the problem of the nature of truth.

I have illustrated our third motive at length. Shall I now try to name it? Well, I should say that it is at bottom the same motive that lay at the basis of Kant's Critical Philosophy; but it is this motive altered by the influence of the modern spirit. It is the motive which leads us to seek for clear and exact self-consciousness regarding the principles both of our belief and of our conduct. This motive leads us to be content only in case we can indeed find principles of knowledge and of action,--principles, not mere transient expediences, and not mere caprices. On the other hand, this motive bids us decline to accept mere authority regarding our principles. It requires of us freedom along with insight, exactness side by side with assurance, and self-criticism as well as search for the ultimate.

\section{IV}

In thus sketching for you these three motives, I have been obliged to suggest my estimate of their significance. But this estimate has so far been wholly fragmentary. Let me next indicate the sense in which I believe that each of these three motives tends, in a very important sense, to throw light upon the genuine theory of truth.

I begin here with the first of the three motives,-namely, with the motive embodied in recent instrumentalism. Instrumentalism views truth as simply the value belonging to certain ideas in so far as these ideas are biological functions of our organisms, and psychological functions whereby we direct our choices and attain our successes.

Wide and manifold are the inductive evidences which the parti- 
sans of such theories of truth adduce in support of their theory. There is the evidence of introspection and of the modern psychological theory of the understanding. Opinions, beliefs, ideas, - what are they all but accompaniments of the motor processes whereby, as a fact, our organisms are adjusted to their environment? To discover the truth of an idea, what is that for any one of us to observe our success in our adjustment to our situation? Knowledge is power. Common sense long ago noted this fact. Empiricism has also since taught us that we deal only with objects of experience. The new instrumentalism adds to the old empiricism simply the remark that we possess truth in so far as we learn how to control these objects of experience. And to this more direct evidence for the instrumental theory of truth is added the evidence derived from the whole work of the modern sciences. In what sense are scientific hypotheses and theories found to be true? Only in this sense, says the instrumentalist,-only in this sense, that through these hypotheses we acquire constantly new sorts of control over the course of our experience. If we turn from scientific to moral truth, we find a similar result. The moral ideas of any social order are practical plans and practical demands in terms of which this social order endeavors, by controlling the activities of its members, to win general peace and prosperity. The truth of moral ideas lies solely in this their empirical value in adjusting individual activities to social demands, and in thus winning general success for all concerned.

Such are mere hints of the evidences that can be massed to illustrate the view that the truth of ideas is actually tested, and is to be tested, by their experienced workings, by their usefulness in enabling man to control his empirically given situation. If this be the case, then truth is always relative to the men concerned, to their experience, and to their situations. Truth grows, changes, and refuses to be tested by absolute standards. It happens to ideas, in so far as they work. It belongs to them when one views them as instruments to an end. The result of all this is a relativistic, an evolutionary, theory of truth. For such a view logic is a part of psychology,-a series of comments upon certain common characteristics of usefully working ideas and opinions. Ethical theory is a branch of evolutionary sociology. And in general, if you want to test the truth of ideas and opinions, you must look forward to their workings, not backward to the principles from which they might 
be supposed to follow, nor yet upwards to any absolute standards which may be supposed to guide them, and least of all to any realm of fixed facts that they are supposed to be required, willy nilly, to copy. Truth is no barren repetition of a dead reality, but belongs, as a quality, to the successful deeds by which we produce for ourselves the empirical realities that we want.

Such is the sort of evidence which my friends, Professor James and Professor Dewey, and their numerous followers, in recent discussion, have advanced in favor of this instrumental, practical, and evolutionary theory of truth. Such are the considerations which, in other forms, Mach has illustrated by means of his history and analyses of the work of modern science.

Our present comment upon this theory must be given in a word. It contains indeed a report of the truth about our actual human life, and about the sense in which we all seek and test and strive for truth, precisely in so far as truth-seeking is indeed a part of our present organic activities. But the sense in which this theory is thus indeed a true account of a vast range of the phenomena of human life is not reducible to the sense which the theory itself ascribes to the term "truth."

For suppose I say, reporting the facts of the history of science: "Newton's theory of gravitation proved to be true, and its truth lay in this: The definition and the original testing of the theory consisted in a series of the organic and psychological functions of the live creature Newton. His theories were for him true in so far as, after hard work, to be sure, and long waiting, they enabled him to control and to predict certain of his own experiences of the facts of nature. The same theories are still true for us because they have successfully guided, and still guide, certain observations and experiences of the men of to-day." This statement reduces the truth of Newton's theory to the type of truth which instrumentalism demands. But in what sense is my account of this matter itself a true account of the facts of human life? Newton is dead. As mortal man he succeeds no longer. His ideas, as psychological functions, died with him. His earthly experiences ceased when death shut his eyes. Wherein consists to-day, then, the historical truth that Newton ever existed at all, or that the countless other men whom his theories are said to have guided ever lived, or experienced, or succeeded? And if I speak of the men of to-day, in what sense is the statement true that they now live, or have experi- 
ence, or use Newton's theory, or succeed with it as an instrument? No doubt all these historical and socially significant statements of mine are indeed substantially true. But does their truth consist in my success in using the ideal instruments that I use when I utter these assertions? Evidently I mean, by calling these my own assertions true, much more than I can interpret in terms of my experience of their success in guiding my act.

In brief, the truth that historical events ever happened at all; the truth that there ever was a past time, or that there ever will be a future time; the truth that anybody ever succeeds, except in so far as I myself, just now, in the use of these my present instruments for the transient control of my passing experience chance to succeed; the truth that there is any extended course of human experience at all, or any permanence, or any long-lasting success,-well, all such truths, they are indeed true, but their truth cannot possibly consist in the instrumental value which any man ever experiences as belonging to any of his own personal ideas or acts. Nor can this truth consist in anything that even a thousand or a million men can separately experience, each as the success of his own ideal instruments. For no one man experiences the success of any man but himself, or of any instruments but his own; and the truth, say, of Newton's theory consists, by hypothesis, in the perfectly objective fact that generations of men have really succeeded in guiding their experience by this theory. But that this is the fact no man, as an individual man, ever has experienced or will experience under human conditions.

When an instrumentalist, then, gives to us his account of the empirical truth that men obtain through using their ideas as instruments to guide and to control their own experience, his account of human organic and psychological functions may be,-yes, is,-as far as it goes, true. But if it is true at all, then it is true as an account of the characters actually common to the experience of a vast number of men. It is true, if at all, as a report of the objective constitution of a certain totality of facts which we call human experience. It is, then, true in a sense which no man can ever test by the empirical success of his own ideas as his means of controlling his own experiences. Therefore the truth which we must ascribe to instrumentalism, if we regard it as a true doctrine at all, is precisely a truth, not in so far as instrumentalism is itself an instrument for helping on this man's or that man's way of controlling his experi- 
ence. If instrumentalism is true, it is true as a report of facts about the general course of history, of evolution, and of human experience,-facts which transcend every individual man's experience, verifications, and successes. To make its truth consist in the mere sum of the various individual successes is equally vain, unless indeed that sum is a fact. But no individual man ever experiences that fact.

Instrumentalism, consequently, express no motive which by itself alone is adequate to constitute any theory of truth. And yet, as I have pointed out, I doubt not that instrumentalism gives such a substantially true account of man's natural functions as a truth seeker. Only the sense in which instrumentalism is a true account of human life is opposed to the adequacy of its own definition of truth. The first of our three motives is, therefore, useful only if we can bring it into synthesis with other motives. In fact it is useless to talk of the success of the human spirit in its efforts to win control over experience, unless there is indeed a human spirit which is more than any man's transient consciousness of his own efforts, and unless there is an unity of experience, and unity objective, real, and supratemporal in its significance.

$\mathbf{V}$

Our result so far is that man indeed uses his ideas as means of controlling his experience, and that truth involves such control, but that truth cannot be defined solely in terms of our personal experience of our own success in obtaining this control.

Hereupon the second of the motives which we have found influencing the recent theories of truth comes to our aid. If instrumentalism needs a supplement, where are we, the individual thinkers, to look for that supplement, except in those inner personal grounds which incline each of us to make his own best interpretation of life precisely as he can, in accordance with his own will to succeed, and in accordance with his individual needs?

To be sure, as one may still insist, we are always dealing with live human experience, and with its endless constraints and limitations. And when we accept or reject opinions, we do so because, at the time, these opinions seem to us to promise a future empirical "working," a successful "control" over experience,-in brief, a success such as appeals to live human beings. Instrumentalism in so far correctly defines the nature which truth possesses in so far 
as we ever actually verify truth. And of course we always believe as we do because we are subject to the constraint of our present experience. But since we are social beings, and beings with countless and varied intelligent needs, we constantly define and accept as valid very numerous ideas and opinions whose truth we do not hope personally to verify. Our act in accepting such unverified truths is (as Professor James states the case) essentially similar to the act of the banker in accepting credit values instead of cash. A note or other evidence of value is good if it can be turned into cash at some agreed time, or under specified conditions. Just so, an idea is true, not merely at the moment when it enables somebody to control his own experience. It is true if, under definable conditions which, as a fact, you or I may never verify, it would enable some human being whose purposes agree with ours to control his own experience. If we personally do not verify a given idea, we can still accept it then upon its credit value. We can accept it precisely as paper, which cannot now be cashed, is accepted by one who regards that paper as, for a given purpose, or to a given extent, equivalent to cash. A bond, issued by a government, may promise payment after fifty years. The banker may today accept such a bond as good, and may pay cash for it, although he feels sure that he personally will never live to see the principal repaid by the borrower.

Now, as Professor James would say, it is in this sense that our ideas about past time, and about the content of other men's minds, and about the vast physical world, "with all its stars and milky ways," are accepted as true. Such ideas have for us credit values. We accept these ideas as true because we need to trade on credits. Borrowed truth is as valuable in the spiritual realm as borrowed money is in the commercial realm. To believe a now unverified truth is simply to say: "I accept that idea, upon credit, as equivalent to the cash payments in terms of live experience which, as I assert, I could get in case I had the opportunity."

And so much it is indeed easy to make out about countless assertions which we all accept. They are assertions about experience, but not about our present experience. They are made under various constraints of convention, habit, desire, and private conviction, but they are opinions whose truth is for us dependent upon our personal assent and acquiescence.

Herewith, however, we face what is, for more than one modern 
theory of truth, a very critical question. Apparently it is one thing to say: "I accept this opinion upon credit," and quite another thing to say: "The truth of this opinion consists, solely and essentially, in the fact that it is credited by me." In seeming, at least, it is one thing to assert: "We trade upon credit; we deal in credits," and quite another thing to say: "There is no value behind this bond or behind this bit of irredeemable paper currency, except its credit value." But perhaps a modern theory of truth may decline to accept such a difference as ultimate. Perhaps this theory may say: The truth is the credit. As a fact, a vast number of our human opinions-those, for instance, which relate to the past, or to the contents of other men's minds-appear, within the range of our personal experience, as credits whose value we, who believe the opinions, cannot hope ever to convert into the cash of experience. The banker who holds the bond not maturing within his own lifetime can, after all, if the bond is good, sell it to-day for cash. And that truth which he can personally and empirically test whenever he wants to test, is enough to warrant his act in accepting the credit. But I, who am confident of the truths of history, or of geology, or of physics, and who believe in the minds of other men, -I accept as valid countless opinions that are for me, in my private capacity and from an empirical point of view, nothing but irredeemable currency. In vain do I say: "I could convert these ideas into the cash of experience if I were some other man, or if I were living centuries ago instead of to-day." For the question simply recurs: In what sense are these propositions about my own possible experience true when I do not test their truth,-yes, true although I, personally, cannot test their truth? These credits, irredeemable in terms of the cash of my experience,-wherein consists their true credit value?

Here one apparently stands at the parting of the ways. One can answer this question by saying: "The truth of these assertions (or their falsity, if they are false) belongs to them whether I credit them or no, whether I verify them or not. Their truth or their falsity is their own character and is independent of my credit and my verification." But to say this appears to be, after all, just the intellectualism which so many of our modern pragmatists condemn. There remains, however, one other way. One can say: "The truth of the unverified assertions consists simply in the fact that, for our own private and individual ends, they are credited. Credit 
is relative to the creditor. If he finds that, on the whole, it meets his purpose to credit, he credits. And there is no truth, apart from present verifications, except this truth of credit." In other words, that is true for me which I find myself accepting as my way of reacting to my situation.

This, I say, is a theory of truth which can be attempted. Consider what a magnificent freedom such a theory gives to all of us. Credit is relative to the creditor. To be sure, if ever the day of reckoning should come, one would be subject, at the moment of verification, to the constraints of experience. At such times, one would either get the cash or would not get it. But after all very few of our ideas about this great and wonderful world of ours ever are submitted to any such sharp tests. History and the minds of other men, -well, our personal opinions about these remain credits that no individual amongst us can ever test for himself. As your world is mainly made up of such things, your view of your world remains, then, subject to your own needs. It ought to be thus subject. There is no absolute truth. There is only the truth that you need. Enter into the possession of your spiritual right. Borrow Nietzsche's phraseology. Call the truth of ordinary intellectualism mere Sklavenwabrheit. It pretends to be absolute; but only the slaves believe in it. "Henceforth," so some Zarathustra of a new theory of truth may say, "I teach you Herrenwabrbeit." Credit what you choose to credit. Truth is made for man, not man for truth. Let your life "boil over" into new truth as much as you find such effervescence convenient. When, apart from the constraints of present verification, and apart from mere convention, I say: "This opinion of mine is true," I mean simply: "To my mind, lord over its own needs, this assertion now appears expedient." Whenever my expediency changes, my truth will change.

But does anybody to-day hold just this theory of truth? I hesitate to make accusations which some of my nearest and dearest friends may repudiate as personally injurious. But this I can say: I find a great many recent theorists about truth talking in just this spirit so long as they feel free to glorify their spiritual liberty, to amuse their readers with clever assaults upon absolutism, and to arouse sympathy by insistence upon the human and the democratic attractiveness of the novel views of truth that they have to advance. Such individualism, such capriciousness, is in the air. Our modern theorists of truth frequently speak in this way. When their ex- 
pressions of such views are criticized, they usually modify and perhaps withdraw them. What, as individuals, such teachers really mean, I have no right to say. Nobody but themselves can say; and some of them seem to say whatever they please. But this I know; Whoever identifies the truth of an assertion with his own individual interest in making that assertion may be left to bite the dust of his own confusion in his own way and time. The outcome of such essential waywardness is not something that you need try to determine through controversy. It is self-determined. For in case I say to you: "The sole ground for my assertions is this, that I please to make them,"-well, at once I am defining exactly the attitude which we all alike regard as the attitude of one who chooses not to tell the truth. And if, hereupon, I found a theory of truth upon generalizing such an assertion,--well, I am defining as truth-telling precisely that well-known practical attitude which is the contradictory of the truth-telling attitude. The contrast is not one between intellectualism and pragmatism. It is the contrast between two well-known attitudes of will,--the will that is loyal to truth as an universal ideal, and the will that is concerned with its own passing caprices. If I talk of truth, I refer to what the truthloving sort of will seeks. If hereupon I define the true as that which the individual personally views as expedient in opinion or in assertion, I contradict myself, and may be left to my own confutation. For the position in which I put myself, by this individualistic theory of truth, is closely analogous to the position in which Epimenides the Cretan, the hero of the fallacy of the liar, was placed by his own so famous thesis.

\section{VI}

And yet, despite all this, the modern assault upon mere intellectualism is well founded. The truth of our assertions is indeed definable only by taking account of the meaning of our own individual attitudes of will, and the truth, whatever else it is, is at least instrumental in helping us towards the goal of all human volition. The only question is whether the will really means to aim at doing something that has a final and eternal meaning.

Herewith I suggest a theory of truth which we can understand only in case we follow the expressions of the third of the three 
modern motives to which I have referred. I have said that the new logic and the new methods of reasoning in the exact sciences are just now bringing us to a novel comprehension of our relation to absolute truth. I must attempt a very brief indication as to how this is indeed the case.

I have myself long since maintained that there is indeed a logic of the will, just as truly as there is a logic of the intellect. Personally, I go further still. I assert: all logic is the logic of the will. There is no pure intellect. Thought is a mode of action, a mode of action distinguished from other modes mainly by its internal clearness of self-consciousness, by its relatively free control of its own procedure, and by the universality, the impersonal fairness and obviousness of its aims and of its motives. An idea in the consciousness of a thinker is simply a present consciousness of some expression of purpose,-a plan of action. A judgment is an act of a reflective and self-conscious character, an act whereby one accepts or rejects an idea as a sufficient expression of the very purpose that is each time in question. Our whole objective world is meanwhile defined for each of us in terms of our ideas. General assertions about the meaning of our ideas are reflective acts whereby we acknowledge and accept certain ruling principles of action. And in respect of all these aspects of doctrine I find myself at one with recent voluntarism, whether the latter takes the form of instrumentalism, or insists upon some more individualistic theory of truth. But for my part, in spite, or in fact because of this my voluntarism, I cannot rest in any mere relativism. Individualism is right in saying, "I will to credit this or that opinion." But individualism is wrong in supposing that I can ever be content with my own will in as far as it is merely an individual will. The will to my mind is to all of us nothing but a thirst for complete and conscious self-possession, for fullness of life. And in terms of this its central motive, the will defines the truth that it endlessly seeks as a truth that possesses completeness, totality, self-possession, and therefore absoluteness. The fact that, in our human experience, we never meet with any truths such as completely satisfy our longing for insight, this fact we therefore inevitably interpret, not as any defect in the truth, but as a defect in our present state of knowledge, a limitation due to our present type of individuality. Hence we acknowledge a truth which transcends our individual life. Our concepts of the objec- 
tively real world, our ethical ideals of conduct, our estimates of what constitutes the genuine worth of life,-all these constructions of ours are therefore determined by the purpose to conform our selves to absolute standards. We will the eternal. We define the eternal. And this we do whenever we talk of what we call genuine facts or actualities, or of the historical content of human experience, or of the physical world that our sciences investigate. If we try to escape this inner necessity of our whole voluntary and selfconscious life, we simply contradict ourselves. We can define the truth even of relativism only by asserting that relativism is after all absolutely true. We can admit our ignorance of truth only by acknowledging the absoluteness of that truth of which we are ignorant. And all this is no caprice of ours. All this results from a certain necessary nature of our will which we can test as often as we please by means of the experiment of trying to get rid of the postulate of an absolute truth. We shall find that, however often we try this experiment, the denial that there is any absolute truth simply leads to its own denial, and reinstates what it denies.

The reference that I a little while since made to our assertions regarding the past, and regarding the minds of other men, has already suggested to us how stubbornly we all assert certain truths which, for every one of us, transcend empirical verification, but which we none the less regard as absolutely true. If I say: "There never was a past," I contradict myself, since I assume the past even in asserting that a past never was. As a fact our whole interpretation of our experience is determined, in a sense akin to that which Kant defined, by certain modes of our own activity, whose significance is transcendental, even while their whole application is empirical. These modes of our activity make all our empirical sciences logically possible. Meanwhile it need not surprise us to find that Kant's method of defining these modes of our activity was not adequate, and that a new logic is giving us, in this field, new light. The true nature of these necessary modes of our activity becomes most readily observable to us in case we rightly analyze the methods and concepts, not of our own empirical, but rather of our mathematical sciences. For in these sciences our will finds its freest expression. And yet for that very reason in these sciences the absoluteness of the truth which the will defines is most obvious. The new logic to which I refer is especially a study of the logic of mathematics. 


\section{VII}

That there are absolutely true propositions, the existence of the science of pure mathematics proves. It is indeed the case that, as Russell insists, the propositions of pure mathematics are (at least in general) hypothetical propositions. But the hypothetical character of the propositions of pure mathematics does not make the truth that a certain mathematically interesting consequent follows from a certain antecedent, in any way less than absolutely true. The assertion, " $a$ implies $b$," where $a$ and $b$ are propositions, may be an absolutely true assertion; and, as a fact, the hypothetical assertions of pure mathematics possess this absolutely true character. Now it is precisely the nature and ground of this absoluteness of purely mathematical truth upon which recent research seems to me to have thrown a novel light. And the light which has appeared in this region seems to me to be destined to reflect itself anew upon all regions and types of truth, so that empirical and contingent, and historical and psychological and ethical truth, different as such other types of truth may be from mathematical truth, will nevertheless be better understood, in future, in the light of the newer researches into the logic of pure mathematics. I can only indicate, in the most general way, the considerations which I here have in mind.

At the basis of every mathematical theory,-as, for instance, at the basis of pure geometry, or pure number theory,-one finds a set of fundamental concepts, the so-called "indefinables" of the theory in question, and a set of fundamental "propositions," the socalled "axioms" of this theory. Modern study of the logic of pure mathematics has set in a decidedly novel light the question: What is the rational source, and what is the logical basis of these primal concepts and of these primal propositions of mathematical theory? I have no time here to deal with the complications of the recent discussion of this question. But so much I can at once point out: there are certain concepts and certain propositions which possess the character of constituting the doctrine which may be called, in the modern sense, Pure Logic. Some of these concepts and propositions were long ago noted by Aristotle. But the Aristotelian logic actually took account of only a portion of the concepts of pure logic, and was able to give, of these concepts, only a very insufficient analysis. There is a similar inadequacy about the much later 
analysis of the presuppositions of logic which Kant attempted. The theory of the categories is in fact undergoing, at present, a very important process of reconstruction. And this process is possible just because we have at present discovered wholly new means of analyzing the concepts and propositions in question. I refer (as I may in passing state) to the means supplied by modern Symbolic Logic.

Well, the concepts of pure logic, when once defined, constitute an inexhaustible source for the constructions and theories of pure mathematics. A set of concepts and of propositions such as can be made the basis of a mathematical theory is a set possessing a genuine and unquestionable significance if, and only if, these concepts and these propositions can be brought into a certain definite relation with the concepts and propositions of pure logic. This relation may be expressed by saying that if the conditions of general logical theory are such as to imply the valid possibility of the mathematical definitions and constructions in question, then-but only then-are the corresponding mathematical theories at once absolutely valid and significant. In brief, pure mathematics consists of constructions and theories based wholly upon the conceptions and propositions of pure logic.

The question as to the absoluteness of mathematical truth hereupon reduces itself to the question as to the absolutenesss of the truths of pure logic.

Wherein, however, consists this truth of pure logic? I answer, at once, in my own way. Pure logic is the theory of the mere form of thinking. But what is thinking? Thinking, I repeat, is simply our activity of willing precisely in so far as we are clearly conscious of what we do and why we do it. And thinking is found by us to possess an absolute form precisely in so far as we find that there are certain aspects of our activity which sustain themselves even in and through the very effort to inhibit them. One who says: "I do not admit that for me there is any difference between saying yes and saying no,"-says "no," and distinguishes negation from affirmation, even in the very act of denying this distinction. Well, affirmation and negation are such self-sustaining forms of our will activity and of our thought activity. And such self-sustaining forms of activity determine absolute truths. For instance, it is an absolute truth that there is a determinate difference between the assertion and the denial of a given proposition, and between 
the doing and the not doing of a given deed. Such absolute truths may appear trival enough. Modern logical theory is for the first time making clear to us how endlessly wealthy in consequences such seemingly trivial assertions are.

The absoluteness of the truths of pure logic is shown through the fact that you can test these logical truths in this reflective way. They are truths such that to deny them is simply to reassert them under a new form. I fully agree, for my own part, that absolute truths are known to us only in such cases as those which can be tested in this way. I contend only that recent logical analysis has given to us a wholly new insight as to the fruitfulness of such truths.

\section{VIII}

An ancient example of a use of that way of testing the absoluteness of truth which is here in question is furnished by a famous proof which Euclid gave of the theorem, according to which there exists no last prime number in the ordinal sequence of the whole numbers. Euclid, namely, proved this theorem by what I suppose to be one device whereby individual instances of absolute truths are accessible to us men. He proved the theorem by showing that the denial of the theorem implies the truth of the theorem. That is, if I suppose that there is a last prime number, I even thereby provide myself with the means of constructing a prime number, which comes later in the series of whole numbers than the supposed "last" prime, and which certainly exists just as truly as the whole numbers themselves exist. Here, then, is one classic instance of an absolute truth.

To be sure Euclid's theorem about the prime numbers is a hypothetical proposition. It depends upon certain concepts and propositions about the whole numbers. But the equally absolute truth that the whole numbers themselves form an endless series, with no last term, has been subjected, in recent times, to wholly new forms of reëxamination by Dedekind, by Frege, and by Russell. The various methods used by these different writers involve substantially the same sort of consideration as that which Euclid already applied to the prime numbers. There are certain truths which you cannot deny without denying the truth of the first principles of pure logic. But to deny these latter principles is 
to reassert them under some other and equivalent form. Such is the common principle at the basis of the recent reëxamination of the concept of the whole numbers. Dedekind, in showing that the existence of the dense ordinal series of the rational numbers implies the existence of the Dedekind Schnitte of this series, discovered still another absolute, although of course hypothetical, truth which itself implies the truth of the whole theory of the so-called real numbers. Now all such discoveries are indeed revelations of absolute truth in precisely this sense, that at the basis of all the concepts and propositions about number there are concepts and propositions belonging to pure logic; while if you deny these propositions of pure logic, you imply, by this very denial, the reassertion of what you deny. To discover this fact, to see that the denial of a given proposition implies the reassertion of that proposition, is not, as Kant supposed, something that you can accomplish, if at all, then only by a process of mere "analysis." On the contrary, Euclid's proof as to the prime numbers, and the modern exact proofs of the fundamental theorems of mathematics, involve, in general, a very difficult synthetic process,-a construction which is by no means at first easy to follow. And the same highly synthetic constructions run through the whole of modern logic.

Now once again what does one discover when he finds out such absolute truths? I do not believe, as Russell believes, that one in such cases discovers truths which are simply and wholly independent of our constructive processes. On the contrary, what one discovers is distinctly what I must call a voluntaristic truth,-a truth about the creative will that thinks the truth. One discovers, namely, that our constructive processes, viewed just as activities, possess a certain absolute nature and conform to their own selfdetermined but, for that very reason, absolute laws. One finds out in such cases what one must still, with absolute necessity, do under the presupposition that one is no longer bound by the constraints of ordinary experience, but is free, as one is in pure mathematics free, to construct whatever one can construct. The more, in such cases, one deals with what indeed appear to be, in one aspect, "freie Schöpfungen des menscblichen Geistes," the more one discovers that their laws, which are the fundamental and immanent laws of the will itself, are absolute. For one finds what it is that one must construct even if one denies that, in the ideal world of free construction which one is seeking to define, that 
construction has a place. In brief, all such researches illustrate the fact that while the truth which we acknowledge is indeed relative to the will which acknowledges that truth, still what one may call the pure form of willing is an absolute form, a form which sustains itself in the very effort to violate its own laws. We thus find out absolute truth, but it is absolute truth about the nature of the creative will in terms of which we conceive all truths.

Now it is perfectly true that such absolute truth is not accessible to us in the empirical world, in so far as we deal with individual phenomena. But it is also true that we all of us conceive the unity of the world of experience-the meaning, the sense, the connection of its facts-in terms of those categories which express precisely this very form of our creative activity. Hence, although every empirical truth is relative, all relative truth is inevitably defined by us as subject to conditions which themselves are absolute. This, which Kant long ago maintained, gets a very new meaning in the light of recent logic,-a far deeper meaning, I think, than Kant could conceive.

In any case, the new logic, and the new mathematics, are making us acquainted with absolute truth, and are giving to our knowledge of this truth a clearness never before accessible to human thinking. And yet the new logic is doing all this in a way that to my mind is in no wise a justification of the intellectualism which the modern instrumentalists condemn. For what we hereby learn is that all truth is indeed relative to the expression of our will, but that the will inevitably determines for itself forms of activity which are objectively valid and absolute, just because to attempt to inhibit these forms is once more to act, and is to act in accordance with them. These forms are the categories both of our thought and of our action. We recognize them equally whether we consider, as in ethics, the nature of reasonable conduct, or, as in logic, the forms of conceptual construction, or, as in mathematics, the ideal types of objects that we can define by constructing, as freely as possible, in conformity with these forms. When we turn back to the world of experience, we inevitably conceive the objects of experience in terms of our categories. Hence the unity and the transindividual character which rightly we assign to the objects of experience. What we know about these objects is always relative to our human needs and activities. But all of this relative knowledge is-however provisionally-defined in terms of absolute principles. And that is 
why the scientific spirit and the scientific conscience are indeed the expression of motives, which you can never reduce to mere instrumentalism, and can never express in terms of any individualism. And that is why, wherever two or three are gathered together in any serious moral or scientific enterprise, they believe in a truth which is far more than the mere working of any man's ephemeral assertions.

In sum, an absolute truth is one whose denial implies the reassertion of that same truth. To us men, such truths are accessible only in the realm of our knowledge of the forms that predetermine all of our concrete activities. Such knowledge we can obtain regarding the categories of pure logic and also regarding the constructions of pure mathematics. In dealing, on the other hand, with the concrete objects of experience, we are what the instrumentalists suppose us to be, namely, seekers for a successful control over this experience. And as the voluntarists also correctly emphasize, in all our empirical constructions, scientific and practical, we express our own individual wills and seek such success as we can get. But there remains the fact that in all these constructions we are expressing a will which, as logic and pure mathematics teach us, has an universal absolute nature,-the same in all of us. And it is for the sake of winning some adequate expression of this our absolute nature, that we are constantly striving in our empirical world for a success which we never can obtain at any instant, and can never adequately define in any merely relative terms. The result appears in our ethical search for absolute standards, and in our metaphysical thirst for an absolute interpretation of the universe,a thirst as unquenchable as the over-individual will that expresses itself through all our individual activities is itself world-wide, active, and in its essence absolute.

In recognizing that all truth is relative to the will, the three motives of the modern theories of truth are at one. To my mind they, therefore, need not remain opposed motives. Let us observe their deeper harmony, and bring them into synthesis. And then what I have called the trivialities of mere instrumentalism will appear as what what they are,-fragmentary hints, and transient expressions, of that will whose life is universal, whose form is absolute, and whose laws are at once those of logic, of ethics, of the unity of experience, and of whatever gives sense to life. 
Tennyson, in a well-known passage of his "In Memoriam," cries:

Oh living Will that shalt endure

When all that seems shall suffer shock,

Rise in the spiritual rock,

Flow through our deeds and make them pure.

That cry of the poet was an expression of moral and religious sentiment and aspiration; but he might have said essentially the same thing if he had chosen the form of praying: Make our deeds logical. Give our thoughts sense and unity. Give our Instrumentalism some serious unity of eternal purpose. Make our Pragmatism more than the mere passing froth of waves that break upon the beach of triviality. In any case, the poet's cry is an expression of that Absolute Pragmatism, of that Voluntarism, which recognizes all truth as the essentially eternal creation of the Will. What the poet utters is that form of Idealism which seems to me to be indicated as the common outcome of all the three motives that underlie the modern theory of truth. 
